\title{
OPEN Association between moderated level of air pollution and fetal growth: the potential role of noise exposure
}

Anne-Sophie Mariet ${ }^{1,2,3 凶}$ Nadine Bernard ${ }^{4,5}$, Sophie Pujol ${ }^{4,6}$, Paul Sagot $^{7}$, Gérard Thiriez $^{8}$ Didier Riethmuller ${ }^{9}$, Mathieu Boilleaut ${ }^{10}$, Jérôme Defrance ${ }^{11}$, Hélène Houot $^{5}$, Anne-Laure Parmentier ${ }^{4,6}$, Eric Benzenine ${ }^{1,2}$, Frédéric Mauny ${ }^{4,6}$ \& Catherine Quantin ${ }^{1,2,3}$

This study aims to analyze, in a population of singletons, the potential confounding or modifying effect of noise on the relationship between fetal growth restriction (FGR) or small for gestational age (SGA) and environmental exposure to air pollution. All women with single pregnancies living in one of two medium-sized cities (Besançon, Dijon) and who delivered at a university hospital between 2005 and 2009 were included. FGR and SGA were obtained from medical records. Outdoor residential exposure to nitrogen dioxide $\left(\mathrm{NO}_{2}\right)$ and particulate matter $\left(\mathrm{PM}_{10}\right)$ was quantified at the mother's address at delivery over defined pregnancy periods; outdoor noise exposure was considered to be the annual average daily noise levels in the façade of building $\left(\mathrm{L}_{\mathrm{Aeq}, 24 \mathrm{~h}}\right)$. Adjusted odds ratios $\left(\mathrm{OR}_{\mathrm{a}}\right)$ were estimated by multivariable logistic regressions. Among the 8994 included pregnancies, 587 presented FGR and 918 presented SGA. In the two-exposure models, for SGA, the $O R_{a}$ for a $10-\mu \mathrm{g} / \mathrm{m}^{3}$ increase of $\mathrm{PM}_{10}$ during the two last months before delivery was $1.18,95 \% \mathrm{Cl} 1.00-1.41$ and for $\mathrm{FGR}$, these $\mathrm{OR}_{\mathrm{a}}$ were for the first and the third trimesters, and the two last months before delivery: $0.77(0.61-0.97)$, 1.38 (1.12-1.70), and 1.35 (1.11-1.66), respectively. Noise was not associated with SGA or FGR and did not confound the relationship between air pollution and SGA or FGR. These results are in favor of an association between $\mathrm{PM}_{10}$ exposure and fetal growth, independent of noise, particularly towards the end of pregnancy, and of a lack of association between noise and fetal growth.

The question of the influence of environmental conditions during pregnancy on adverse pregnancies outcomes is increasingly studied but remains debated. Among the adverse outcomes of pregnancy, fetal growth abnormalities are associated with poor perinatal outcomes ${ }^{1-6}$ and increase the prevalence of long-term neurodevelopmental, cardiovascular, and endocrine consequences ${ }^{6-9}$.

Among urban environmental exposures, air pollution and noise are the most ubiquitous and relatively correlated $^{10}$.

The exposure to noise induces the release of stress hormones and inflammatory signaling molecules leading to oxidative stress and vascular dysfunction, and the exposure to air pollution has been suspected of increasing oxidative stress and systemic inflammation, and, during pregnancy, it may decrease uterine blood flow and placental fetal exchange, therefore slowing fetal growth ${ }^{8,11-20}$.

\footnotetext{
${ }^{1}$ Service de Biostatistiques et d'Information Médicale, CHU Dijon Bourgogne, 21000 Dijon, France. ${ }^{2}$ Inserm, Clinical Investigation Center of Dijon (Inserm CIC 1432), CHU Dijon Bourgogne, 21000 Dijon, France. ${ }^{3}$ Inserm, Biostatistique, Biomathématique, Pharmacoépidémiologie et Maladies Infectieuses (B2PHI), UMR 1181, Université Bourgogne Franche-Comté, 21000 Dijon, France. 'Laboratoire Chrono-Environnement UMR 6249, CNRS, Université de Bourgogne Franche-Comté, 25000 Besançon, France. '5aboratoire ThéMA UMR 6049, CNRS, Université de Bourgogne Franche-Comté, 25000 Besançon, France. ${ }^{6}$ Unité de Méthodologie en Recherche Clinique, épidémiologie et santé publique, INSERM CIC 1431, CHU de Besançon, 25000 Besançon, France. ${ }^{7}$ Service de Gynécologie-Obstétrique, CHU Dijon Bourgogne, 21000 Dijon, France. ${ }^{8}$ Service de Réanimation Pédiatrique, Néonatalogie et Urgences Pédiatriques, CHU de Besançon, 25000 Besançon, France. ${ }^{9}$ Service de Gynécologie-Obstétrique, CHU de Besançon, 25000 Besançon, France. ${ }^{10}$ Atmo Bourgogne-Franche-Comté, 25000 Besançon, France. ${ }^{11}$ Centre Scientifique et Technique du Bâtiment, Pôle Acoustique et Eclairage, 38400 Saint Martin d'Hères, France. ${ }^{\varpi}$ email: anne-sophie.mariet@chu-dijon.fr
} 
The association between air pollution and fetal growth disorders has been identified in many of studies in various more and less exposed regions of the world, with different pollutants and different fetal growth indicators measured in newborns at term or not: birth weight (BW), low birth weight (LBW), small for gestational age (SGA), or ultrasound antenatal measurements ${ }^{21-25}$. Nieuwenhuijsen's review in 2017 identified studies of the effects of noise on adverse pregnancy outcomes including fetal growth ${ }^{18}$. The authors found low quality evidence for an association between road traffic noise and LBW and SGA. They conclude that good quality studies were needed in various regions, particularly at lower levels of noise, and taking into account confounding factors like air pollution. Indeed, only a few studies have taken into account the effect of the exposure to both air pollution and noise ${ }^{26-32}$. The last two studies were published after the Nieuwenhuijsen's review ${ }^{31,32}$. In London, Smith et al. estimated that $3 \%$ of infants born at term with LBW are directly attributable to residential exposure to $\mathrm{PM}_{2.5}>13.8 \mu \mathrm{g} / \mathrm{m}^{3}$ during pregnancy, and their results suggested little evidence of an independent exposure-response effect of traffic related noise (daytime and night-time road traffic noise) on BW at term ${ }^{32}$. In 2019, Nieuwenhuijsen et al. studied the influence of the urban exposome on BW in six European birth cohorts and found no evidence of an association between road traffic noise or air pollution and BW and LBW at term in co-exposure analyses ${ }^{31}$.

Although the adverse effect of air pollution on fetal growth is generally recognized, the influence of noise remains debated, as does the relative contribution of these two types of pollutants and the potential effects of coexposure on fetal growth. The objective of this study was to explore the potential confounding or modified effect of noise on the relationship between fetal growth and environmental exposure to moderate levels of air pollution.

\section{Material and methods}

Population. For this retrospective study, we included all single pregnancies in women residing in Besançon or in the urban area of Dijon who delivered at the Besançon or Dijon university hospital between 1st January 2005 and 31st December 2009. The Besançon and Dijon university hospitals are level 3 maternities (i.e. with a neonatal intensive care unit). Stillborns and live newborns, whose births occurred after 22 completed weeks of gestation or with birth weight $>500 \mathrm{~g}$, were included. When a woman had several single pregnancies in the study period, only one pregnancy was included after random selection. Hence, the number of women and the number of pregnancies included in the analysis population is the same $(\mathrm{N}=8994)$.

This work is part of the PRECEE program (PREgnancy and Combined Environmental Exposure) and complements results published by Mariet et al. in 2018 on multiple pregnancies, by Barba-Vasseur et al. in 2017 on preterm birth in single pregnancy, and by Brembilla et al. in 2019 on vulnerability markers in pregnant women ${ }^{33-35}$.

Outcomes. Birth weight and fetal growth restriction (FGR) were extracted from the Besançon computerized medical records (DIAMM software (version 7.5, http://www.micro6.fr/mere-enfant.php) developed by the Association of Computerized Users in Pediatrics, Obstetrics and Gynecology ${ }^{36}$ ) and from the Burgundy perinatal network records and paper medical records for Dijon. Births were classified as SGA if birth weight was $<10$ th centile for gestational age (in weeks) and sex. The threshold for the 10th centile of birth weight was estimated in a population of French newborns from single and multiple pregnancies by gestational age and sex ${ }^{36}$. In order to test for a classification effect, SGA was also defined according to another birth weight standard for gestational age and sex, estimated with data from the 2010 perinatal study ${ }^{37}$. According to French, British, and Canadian recommendations, FGR was defined as a defect in fetal growth on two antenatal measurements taken two to three weeks apart ${ }^{38-40}$. FGR was retained according to the ICD10 codes in medical records (O36.5, P05.0, P05.1).

Covariables. All variables available in the medical records were analyzed to detect potential confounders: maternal socioeconomic characteristics, obstetrical history, pregnancy complications and newborn characteristics (Supplementary Table S1).

Maternal age was calculated at delivery and dichotomized with a threshold of 35 years old. Maternal smoking during pregnancy was coded as "present" if active smoking was ticked in the medical records. Malnutrition was defined by pre-pregnancy body mass index lower than 18.5 or by the presence of an ICD10 code of malnutrition in medical records (O25, E43, E44). Obesity was defined by pre-pregnancy body mass index higher than 30. Vaginal bleeding in the second and third trimesters referred to an episode of bleeding after 28 weeks of gestation, including placental abruption and bleeding because of placenta previa (ICD10 codes: O45, O46, O441 and P021). Major infant congenital abnormalities corresponded to any major congenital anomalies according to the European network of population-based registries for the epidemiologic surveillance of congenital anomalies ${ }^{41}$. Infant congenital abnormalities considered for this study were determined before birth or at birth.

The neighborhood socioeconomic level was estimated with a collective socioeconomic index calculated at the geographical scale of the French sub-municipal census block groups (IRIS) defined by the National Institute of Statistic and Economics Studies ${ }^{42}$. Fifty IRIS in Besançon and 113 in the urban area of Dijon were included; population size ranged between 62 and 4811 inhabitants (mean $=2182$ inhabitants). Variables related to family and household, immigration and mobility, employment and income, education and housing were extracted from the 2008 population census database. From among these variables, 39 were selected because of their occurrence in the literature ${ }^{43-45}$. The first component of a principal component analysis (PCA) was used to calculate a standardized socio-economic index following a reduction step. The socioeconomic index was calculated using the R package SesIndexCreatoR ${ }^{43}$. A value of the socioeconomic index in the last decile was considered as low neighborhood socioeconomic level.

Environmental residential exposures. The residential exposure assessments have been previously described ${ }^{10,33-35,46-50}$. The participants' addresses at the date of delivery were extracted from CPage software (ver- 
sion 2, https://www.cpage.fr/) using the personal identification number and the date of delivery. This address identified the residential building.

Two pollutants related to road traffic were studied. $\mathrm{NO}_{2}$ is a gaseous pollutant known to be the main indicator of road traffic $c^{51}$. Particulate matters $\left(\mathrm{PM}_{10}\right)$ are also generated by road traffic and residential heating and were chosen because of their significant impact on human health and climate ${ }^{52,53} \cdot \mathrm{NO}_{2}$ and $\mathrm{PM}_{10}$ exposure assessments were calculated at each mother's building considering a $50 \mathrm{~m}$ radius buffer centered on the building centroid. The $\mathrm{NO}_{2}$ and $\mathrm{PM}_{10}$ levels were calculated using a two-step emission and diffusion modeling. Air pollutant emissions were calculated from road traffic data using CIRCUL'AIR software (version 2.51, www.atmo-grandest.eu), developed and used by all approved French Air Quality Monitoring Agencies (AASQA) (COPERT IV European standard methodology). AASQA's pollution emission inventory was used to assess air pollutant emissions related to all activity sectors, especially heating, industries or agriculture. Air pollutant concentration was estimated $2 \mathrm{~m}$ above ground on a $25 \mathrm{~m}$ grid with reinforced gridding around the axes of emission, using the ADMS-Urban software (version 3.1.6, http://www.cerc.co.uk/) for diffusion modeling. ESRI ArcGIS software (version 10.1, https://www.esrifrance.fr/) was used for spatial interpolation to increase the spatial resolution of the ADMS output. Air pollutant concentration expressed in micrograms per cubic meter $\left(\mu \mathrm{g} / \mathrm{m}^{3}\right)$ was thus calculated at a $4 \mathrm{~m}^{2}(2 \mathrm{~m} \times 2 \mathrm{~m})$ raster. The validity of the $2 \mathrm{~m}$ result was estimated on the basis of data from four, two-weeklong measurement campaigns carried out during autumn and winter 2010 as well as spring and summer 2011. Measurements were based on 863 passive samplers and the nine AASQA air pollution measurement stations for $\mathrm{NO}_{2}$ (ATMO Franche-Comté and Atmosf'Air Bourgogne). Validation statistics ( $\left.\mathrm{r}^{2}\right)$ range from 0.64 to 0.69 . The validity of the $\mathrm{PM}_{10}$ models were verified using the city's fixed air-quality monitoring network. Monthly maps of air pollutant concentration were established from January 2004 to December 2009 using hourly meteorological data and background pollution levels to account for the seasonal variations in air pollutant concentrations. Using the monthly maps, time-weighted average air pollutant exposure was assessed over the following defined pregnancy periods: first, second and third trimester, entire pregnancy and two months before delivery.

Noise levels were calculated in accordance with the European Commission's Environmental Noise Directive 2002/49/CE using an environmental noise prediction model with MithraSIG software (version 3.7, https:// www.geomod.fr/fr/geomatique-modelisation-3d/mithrasig/ $/)^{54}$. The following four types of noise sources were considered: road traffic, rail traffic, pedestrian streets, and fountains. Individual aircraft noise data were not available for the 2005-2009 period (military airport located within the city limits of Dijon). Women living in the area exposed to aircraft noise (according to the urban unit noise exposure plan) were not considered in this study. Theoretical noise levels were calculated in front of each building façade on each floor. Measurement campaigns were used for validation (76 points). The validation was good with a Spearman correlation coefficient at $0.81(p<0.01)$. For each woman, the average building noise levels in front of the entire façade were calculated using the following five indices: the daily equivalent $\mathrm{A}$-weighted total noise level, $\mathrm{L}_{\text {Aeq,24 }}$ for principal analysis; day equivalent $\mathrm{A}$-weighted total noise level $\mathrm{L}_{\text {Aeq,day }}(6: 00-18: 00 \mathrm{~h})$; evening equivalent $\mathrm{A}$-weighted noise level $\mathrm{L}_{\text {Aeq,evening }}(18: 00-22: 00 \mathrm{~h})$; night equivalent A-weighted total noise level $\mathrm{L}_{\text {Aeq,night }}(22: 00-6: 00 \mathrm{~h})$; and combined day-evening-night $\mathrm{A}$-weighted total noise level $\mathrm{L}_{\mathrm{den}}$, with evening and night exposures penalized by 5 and $10 \mathrm{~dB}$, respectively, for sensitivity analyses. Moreover, source-specific indices for $\mathrm{L}_{\mathrm{Aeq}, 24 \mathrm{~h}}$ were calculated for road and rail traffic related noise for sensitivity analyses.

Statistics. The association between environmental exposures $\left(\mathrm{NO}_{2}, \mathrm{PM}_{10}\right.$ and $\left.\mathrm{L}_{\mathrm{Aeq}, 24 \mathrm{~h}}\right)$ and SGA or FGR was estimated with simple and multiple logistic regression analyses, in single, and two-exposure models (air pollution with noise), where SGA or FGR were taken as binary outcomes in the models. Departure from the assumption of linearity was tested by introducing a polynomial function of the environmental exposure variables into the models. The ORs were adjusted for: term in gestational weeks, maternal age older than 35 years at delivery, low neighborhood socioeconomic level, maternal smoking during pregnancy, malnutrition and obesity, nulliparity, gestational hypertension, diabetes, assisted reproductive techniques, vaginal bleeding in the second and third trimesters, infection, and major infant congenital abnormalities. Because of the non-random distribution of missing data, a missing data class was used for categorical variables in multivariate analysis. Only two adjustment factors of the model had missing data: malnutrition and obesity $(\mathrm{n}=219)$ and maternal smoking during pregnancy $(n=196)$, affecting only $2.4 \%$ of pregnancies. Potential interactions between air pollution and noise indices were assessed in models where at least one exposure was significant ( $p$-value $<0.15)$. The interaction was tested using the $p$-value associated with the term from the regression analysis and comparing the Akaike Information Criterion (AIC) of models with and without the interaction term. Sensitivity analyses were conducted using four noise indices $\left(\mathrm{L}_{\text {Aeq,day }}, \mathrm{L}_{\text {Aeq,evening, }}, \mathrm{L}_{\text {Aeq,night }}, \mathrm{L}_{\text {den }}\right.$ ), two source-specific noise indices (road and rail traffic related noise $\mathrm{L}_{\text {Aeq,24h }}$ ), and the other birth weight standard to define SGA as an outcome variable ${ }^{37}$. Maternal age at delivery and neighborhood socioeconomic level were also considered for adjustment in continuous form, or with a 2 nd or 3rd order polynomial. Adjustment for year-season of conception was also considered in sensitivity analysis. Finally, a last analysis was conducted restricted to the subgroup of live births. Statistical analyses were performed with SAS software (version 9.4, SAS Institute, Cary, NC: https://www.sas.com/).

Ethics. This study was approved by the French National Advisory Committee for the Treatment of Information in Health Research (CCTIRS) (registration number 15.292, April 9th 2015) and by the French data protection authority (CNIL) (registration number DR-2015-736, December 24th 2015). All methods were carried out in accordance with the ethical standards of CNIL and the Declaration of Helsinki. The requirement for patient informed consent was waived by the CNIL because of the retrospective nature of the study. A letter of information was sent to each eligible participant, and 20 families refused to participate. They were excluded from the study. All records were anonymized prior to analysis. 


\section{Consent to participate}

The requirement for patient informed consent was waived by the CNIL because of the retrospective nature of the study. So, in accordance with the CNIL recommendations, a letter of information was sent to each eligible family and those who refused to participate where not included.

\section{Results}

Among the 10570 single deliveries which occurred in the Besançon or Dijon university hospital from women over 18 years old and living in the defined study area, 8994 pregnancies were included in the study. Twenty pregnancies were excluded because the family opposed the use of their medical data, 103 due to incorrect address (wrong or unrecognizable recorded street names or anonymous childbirth) and 1453 pregnancies were excluded because the same woman had several pregnancies over the study period.

Among the 8994 pregnancies, 587 had FGR and 918 had SGA. Five hundred and five (55.0\%) fetuses with SGA did not have FGR; and 172 (29.4\%) fetuses with FGR did not have SGA. SGA and FGR were significantly associated ( $p$-value $<0.0001$, Chi-square test). The pregnancy and newborn characteristics are presented in Table 1.

The median $\mathrm{NO}_{2}$ concentration considering a $50 \mathrm{~m}$ radius buffer during the entire pregnancy was $23.2 \mu \mathrm{g} / \mathrm{m}^{3}$; the minimum exposure was $7.4 \mu \mathrm{g} / \mathrm{m}^{3}$ and the maximum exposure was $51.6 \mu \mathrm{g} / \mathrm{m}^{3}$ (Supplementary Figure S1, Supplementary Table S2). The median $\mathrm{PM}_{10}$ concentration considering a $50 \mathrm{~m}$ radius buffer during the entire pregnancy was $18.5 \mu \mathrm{g} / \mathrm{m}^{3}$; the minimum exposure was $11.9 \mu \mathrm{g} / \mathrm{m}^{3}$ and the maximum exposure was $31.5 \mu \mathrm{g} /$ $\mathrm{m}^{3}$ (Supplementary Figure S2, Supplementary Table S2). The median daily equivalent A-weighted total noise level was $55.5 \mathrm{~dB}$; the minimum exposure was $33.2 \mathrm{~dB}$ and the maximum exposure was $76.9 \mathrm{~dB}$ (Supplementary Figure S3, Supplementary Table S2). The Pearson correlation coefficients for environmental exposure were: 0.56 between $\mathrm{L}_{\text {Aeq, } 24 \mathrm{~h}}$ and $\mathrm{NO}_{2}$ exposure during the entire pregnancy, 0.28 between $\mathrm{L}_{\text {Aeq,24h }}$ and $\mathrm{PM}_{10}$ exposure during the entire pregnancy, and 0.28 between $\mathrm{NO}_{2}$ and $\mathrm{PM}_{10}$ exposure during the entire pregnancy $\left(p\right.$-value $\left.<10^{-3}\right)$ (Supplementary Table S3).

We found no departure from the assumption of linearity of pregnancy outcomes with noise and air pollution (Supplementary Figure S4).

For SGA, the crude OR associated with a $5 \mathrm{~dB}$ increase of total building $\mathrm{L}_{\text {Aeq, } 24 \mathrm{~h}}$ was 0.97 (95\% CI 0.91-1.03) (Table 2). The adjusted OR remained similar in single and two-exposure models. The crude OR associated with a $10 \mu \mathrm{g} / \mathrm{m}^{3}$ increase in $\mathrm{NO}_{2}$ exposure during the first, second and third trimester, the entire pregnancy and the two months before delivery were 0.94 (95\% CI 0.86-1.02), 0.96 (95\% CI 0.87-1.04), 0.95 (95\% CI 0.87-1.04), 0.94 (95\% CI 0.86-1.03), and 0.96 (95\% CI 0.88-1.05), respectively. The adjusted OR remained similar in singleexposure models and in two-exposure models with total building $\mathrm{L}_{\text {Aeq,24h }}$. The crude OR associated with a $10 \mu \mathrm{g} / \mathrm{m}^{3}$ increase in $\mathrm{PM}_{10}$ exposure during the first, second and third trimester, the entire pregnancy and the two months before delivery were 1.02 (95\% CI 0.86-1.22), 1.17 (95\% CI 0.99-1.39), 1.21 (95\% CI 1.03-1.43), 1.29 (95\% CI 1.00-1.66), and 1.20 (95\% CI 1.02-1.41), respectively. The adjusted OR in single-exposure models decreased slightly and became non-significant. In the two-exposure models with total building $\mathrm{L}_{\text {Aeq,24h }}$, only the adjusted $\mathrm{OR}$ associated with a $10 \mu \mathrm{g} / \mathrm{m}^{3}$ increase in $\mathrm{PM}_{10}$ exposure during the two months before delivery was significant: 1.18 (95\% CI 1.00-1.40). Sensitivity analyses were conducted using the birth weight standard of Ego (Cf. Material and methods). The proportion of pregnancies with SGA was $12.4 \%$. Sensitivity analyses led to OR estimates close to the main analysis.

When considering FGR, the crude OR associated with a $5 \mathrm{~dB}$ increase of total building $\mathrm{L}_{\text {Aeq, } 24 \mathrm{~h}}$ was 0.98 ( $95 \%$ CI 0.90-1.06) (Table 2). The adjusted OR remained similar in single and two-exposure models. The crude OR associated with a $10 \mu \mathrm{g} / \mathrm{m}^{3}$ increase in $\mathrm{NO}_{2}$ exposure during the first, second and third trimester, the entire pregnancy and the two months before delivery were 0.93 (95\% CI 0.83-1.03), 1.00 (95\% CI 0.90-1.11), 1.03 (95\% CI 0.93-1.15), 0.98 (95\% CI 0.88-1.10), and 1.04 (95\% CI 0.93-1.16), respectively. The adjusted OR remained similar in single and two-exposure models with values close to 1 . The crude OR associated with a $10 \mu \mathrm{g} / \mathrm{m}^{3}$ increase in $\mathrm{PM}_{10}$ exposure during the first, second and third trimester, the entire pregnancy and the two months before delivery were 0.78 (95\% CI 0.63-0.98), 1.02 (95\% CI 0.82-1.26), 1.39 (95\% CI 1.14-1.70), 1.05 (95\% CI 0.77-1.43), and 1.35 (95\% CI 1.11-1.63), respectively. The adjusted OR remained similar in single and two-exposure models.

For SGA, the OR for single-exposure adjusted models for an increase of an IQR were 0.95 (95\% CI 0.87-1.05) for total building $\mathrm{L}_{\text {Aeq, } 24 \mathrm{~h}}, 0.92$ (95\% CI 0.84-1.02) for $\mathrm{NO}_{2}$ exposure during the third trimester, and $1.08(95 \%$ CI 0.99-1.18) for $\mathrm{PM}_{10}$ exposure during the third trimester, respectively. For FGR, they were 0.97 (95\% CI 0.87-1.09) for building $\mathrm{L}_{\text {Aeq,24 } \mathrm{h}}, 1.01$ (95\% CI 0.89-1.14) for $\mathrm{NO}_{2}$ exposure during the third trimester, and 1.16 (95\% CI 1.05-1.29) for $\mathrm{PM}_{10}$ exposure during the third trimester, respectively.

The two centers differed on characteristics of the pregnancy, for example: low neighborhood socioeconomic level (16.2 for Besançon versus 13.4\% for Dijon), malnutrition (9.1\% for Besançon versus 6.6\% for Dijon), prematurity (7.3\% for Besançon versus $8.8 \%$ for Dijon), or small for gestational age ( $11.8 \%$ for Besançon versus $9.1 \%$ for Dijon), but not on FGR (7.0\% for Besançon versus 6.2\% for Dijon). Environmental exposures were significantly different between the two centers: in Besançon, noise and $\mathrm{NO}_{2}$ levels were lower, but $\mathrm{PM}_{10}$ levels were higher (Supplementary Table S4). Adjustment for the maternity of delivery has been tested and stratified analyses on the maternity of delivery have been performed. In the adjusted analysis, OR associated with total noise exposure remained similar and did not change the OR associated with air pollution exposure in the two-exposure models. The results were also similar in the stratified analyses. For example, for FGR, OR associated with a $5 \mathrm{~dB}$ increase of total building $\mathrm{L}_{\text {Aeq, } 24 \mathrm{~h}}$ was 0.93 (95\% CI 0.82-1.05) for Besançon and 1.03 (95\% CI 0.92-1.15) for Dijon, and OR associated with a $10 \mu \mathrm{g} / \mathrm{m}^{3}$ increase in $\mathrm{PM}_{10}$ exposure during the third trimester was 1.33 (95\% CI 1.00-1.75) for Besançon and 1.30 (95\% CI 0.93-1.81) for Dijon in single exposure models. And OR associated with a $10 \mu \mathrm{g} /$ $\mathrm{m}^{3}$ increase in $\mathrm{PM}_{10}$ exposure during the third trimester were 1.41 (95\% CI 1.06-1.88) for Besançon and 1.31 (95\% CI 0.93-1.85) for Dijon in two exposure models. 


\begin{tabular}{|c|c|c|c|c|c|c|}
\hline & \multirow[b]{2}{*}{$\mathbf{N}$} & \multirow{2}{*}{\begin{tabular}{|l|} 
Total \\
$N(\%)$ \\
\end{tabular}} & \multicolumn{2}{|c|}{ Small for gestational age ${ }^{1}$} & \multicolumn{2}{|c|}{ Fetal growth restriction } \\
\hline & & & Yes $N(\%)$ & No $N(\%)$ & Yes $N(\%)$ & No $N(\%)$ \\
\hline Pregnancies & & $\mathrm{N}=8994$ & $\mathrm{~N}=918$ & $\mathrm{~N}=8071$ & $\mathrm{~N}=587$ & $\mathrm{~N}=8407$ \\
\hline City of residence & 8994 & & & & & \\
\hline Besançon & & $3684(41.0)$ & $433(47.2)$ & $3246(40.2)$ & $257(43.8)$ & $3427(40.8)$ \\
\hline Dijon & & $5310(59.0)$ & $485(52.8)$ & $4825(59.8)$ & $330(56.2)$ & $4980(59.2)$ \\
\hline Maternal age at delivery $>35$ years old & 8994 & $1424(15.8)$ & $130(14.2)$ & $1292(16.0)$ & $85(14.5)$ & $1339(15.9)$ \\
\hline Low neighborhood socioeconomic level & 8994 & $1308(14.5)$ & $142(15.5)$ & $1165(14.4)$ & $82(14.0)$ & $1226(14.6)$ \\
\hline Living status & 8577 & & & & & \\
\hline Living alone & & $716(8.4)$ & $104(11.8)$ & $612(8.0)$ & $66(11.8)$ & $650(8.1)$ \\
\hline Married, cohabitation, others & & 7861 (91.6) & $779(88.2)$ & $7077(92.0)$ & $495(88.2)$ & $7366(91.9)$ \\
\hline Maternal employment during pregnancy & 8504 & $5455(64.2)$ & $540(62.1)$ & $4913(64.4)$ & $352(63.0)$ & $5103(64.2)$ \\
\hline Maternal smoking during pregnancy & 8798 & $1665(18.9)$ & $318(35.0)$ & $1346(17.1)$ & $207(36.0)$ & $1458(17.7)$ \\
\hline Pre-pregnancy body mass index $\left(\mathrm{kg} / \mathrm{m}^{2}\right)$ & 8775 & & & & & \\
\hline$<25$ & & $6226(70.9)$ & $694(77.5)$ & $5527(70.2)$ & $457(79.9)$ & $5769(70.3)$ \\
\hline $25-30$ & & $1728(19.7)$ & $133(14.8)$ & $1595(20.3)$ & $80(14.0)$ & $1648(20.1)$ \\
\hline 30 (obesity) & & $821(9.4)$ & $69(7.7)$ & $752(9.5)$ & $35(6.1)$ & $786(9.6)$ \\
\hline Malnutrition & 8775 & $671(7.7)$ & $122(13.6)$ & $549(7.0)$ & $82(14.3)$ & $589(7.2)$ \\
\hline Nulliparity & 8994 & 4809 (53.5) & $593(64.6)$ & $4212(52.2)$ & $392(66.8)$ & $4417(52.5)$ \\
\hline History of medical interruption of pregnancy & 8922 & $130(1.5)$ & $13(1.4)$ & $117(1.5)$ & $9(1.5)$ & $121(1.5)$ \\
\hline History of preterm delivery & 8786 & $164(1.9)$ & $18(2.0)$ & $146(1.9)$ & $12(2.1)$ & $152(1.9)$ \\
\hline Abnormalities of the female reproductive tract & 8994 & $722(8.0)$ & $62(6.8)$ & $658(8.2)$ & $49(8.4)$ & $673(8.0)$ \\
\hline Uterine scar & 8994 & $617(6.9)$ & $50(5.5)$ & $566(7.0)$ & $41(7.0)$ & $576(6.9)$ \\
\hline Assisted reproductive techniques & 8994 & $188(2.1)$ & $21(2.3)$ & $167(2.1)$ & $19(3.2)$ & $169(2.0)$ \\
\hline Gestational hypertension & 8994 & $382(4.3)$ & $74(8.1)$ & $308(3.8)$ & $79(13.5)$ & $303(3.6)$ \\
\hline Vaginal bleeding in the second and third trimesters & 8994 & $222(2.5)$ & $32(3.5)$ & $190(2.4)$ & $29(4.9)$ & $193(2.3)$ \\
\hline Placental abruption & 8994 & $71(0.8)$ & $15(1.6)$ & $56(0.7)$ & $15(2.6)$ & $56(0.7)$ \\
\hline Placenta previa & 8994 & $57(0.6)$ & $6(0.7)$ & $51(0.6)$ & $4(0.7)$ & $53(0.6)$ \\
\hline Hemorrhagic placenta previa & 8994 & $33(0.4)$ & $3(0.3)$ & $30(0.4)$ & $1(0.2)$ & $32(0.4)$ \\
\hline Infection & 8994 & $1258(14.0)$ & $135(14.7)$ & $1123(13.9)$ & $93(15.8)$ & $1165(13.9)$ \\
\hline Infection of amniotic fluid & 8994 & $84(0.9)$ & $8(0.9)$ & $76(0.9)$ & $10(1.7)$ & $74(0.9)$ \\
\hline Genitourinary infection & 8994 & $979(10.9)$ & 99 (10.8) & $880(10.9)$ & $58(9.9)$ & $921(11.0)$ \\
\hline Diabetes & 8994 & $691(7.7)$ & $50(5.5)$ & $641(7.9)$ & $34(5.8)$ & $657(7.8)$ \\
\hline Hydramnios & 8994 & $116(1.3)$ & $6(0.7)$ & $110(1.4)$ & $5(0.9)$ & $111(1.3)$ \\
\hline Premature rupture of membranes & 8994 & $1173(13.0)$ & $91(9.9)$ & $1081(13.4)$ & $76(13.0)$ & $1097(13.1)$ \\
\hline Prematurity $(\leq 36 \mathrm{SA})$ & 8994 & $736(8.2)$ & $92(10.0)$ & $643(8.0)$ & $128(21.8)$ & $608(7.2)$ \\
\hline \multicolumn{7}{|l|}{ Newborns } \\
\hline Status & 8994 & & & & & \\
\hline Living & & $8883(98.8)$ & $886(96.5)$ & $7993(99.0)$ & $577(98.3)$ & $8306(98.8)$ \\
\hline Stillborn & & $98(1.1)$ & $30(3.3)$ & $67(0.8)$ & $9(1.5)$ & $89(1.1)$ \\
\hline Deceased shortly after birth & & $13(0.1)$ & $2(0.2)$ & $11(0.2)$ & $1(0.2)$ & $12(0.1)$ \\
\hline Sex & 8991 & & & & & \\
\hline Male & & $4686(52.1)$ & $470(51.2)$ & $4214(52.2)$ & $251(42.9)$ & $4435(52.8)$ \\
\hline Female & & $4305(47.9)$ & $448(48.8)$ & $3857(47.8)$ & $334(57.1)$ & $3971(47.2)$ \\
\hline Birth weight $(\mathrm{g})$ & 8992 & $3215(597)$ & $2494(515)$ & $3298(548)$ & $2360(546)$ & $3275(553)$ \\
\hline Major infant congenital abnormalities & 8994 & $305(3.4)$ & $32(3.5)$ & $270(3.4)$ & $35(6.0)$ & $270(3.2)$ \\
\hline Apgar score at five minutes $=10$ & 8833 & $8008(90.7)$ & $787(88.7)$ & $7218(90.9)$ & $485(86.0)$ & $7523(91.0)$ \\
\hline
\end{tabular}

Table 1. Pregnancy and newborn characteristics according to fetal growth restriction and small for gestational age status, 2005-2009 ( $\mathrm{N}=8994)$. N: number; N (\%): number (percentage) except for birth weight which is described by mean (standard deviation). ${ }^{1}$ Lower than 10th centile of birth weight for gestational age.

Interactions between noise and air pollution do not improve the adequacy of the models. Furthermore, no synergistic or antagonist effects were observed in the models with the interaction term.

Sensitivity analyses led to similar results when considering road or rail traffic related noise exposure, maternal age or neighborhood socioeconomic level in continuous variable with 1st, or a 2nd or a 3rd order polynomial, or restricted to the subgroup of live births (Supplementary Tables S5, S6, S7, S8, and S9). In the sensitivity analysis with adjustment for year-season of conception, the OR for the association between first trimester $\mathrm{PM}_{10}$ 


\begin{tabular}{|c|c|c|c|c|c|c|c|c|}
\hline & \multicolumn{2}{|l|}{ Outcome } & \multicolumn{6}{|c|}{ OR $[95 \% \mathrm{CI}]$ for an increase of $5 \mathrm{~dB}$ or $10 \mu \mathrm{g} / \mathrm{m}^{3}$} \\
\hline & \multirow[b]{2}{*}{ Yes $\mu(S D)$} & \multirow[b]{2}{*}{ No $\mu(S D)$} & \multicolumn{4}{|c|}{ Single-exposure models } & \multicolumn{2}{|c|}{$\begin{array}{l}\text { Two-exposure noise and air } \\
\text { pollution models }\end{array}$} \\
\hline & & & Crude OR & $p$-value ${ }^{1}$ & Adjusted $\mathrm{OR}^{2}$ & $p$-value ${ }^{1}$ & Adjusted $\mathrm{OR}^{2}$ & $p$-value ${ }^{1}$ \\
\hline $\begin{array}{l}\text { Small for gesta- } \\
\text { tional age }\end{array}$ & $\mathrm{N}=918$ & $\mathrm{~N}=8071$ & $\mathrm{~N}=8989$ & & $\mathrm{~N}=8989$ & & $\mathrm{~N}=8989$ & \\
\hline \multicolumn{7}{|c|}{ Total noise exposure (dB) building $\mathrm{L}_{\text {Aeq, } 24 \mathrm{~h}}$} & $1.00[0.92 ; 1.08]^{6}$ & 0.89 \\
\hline Entire pregnancy ${ }^{3}$ & $55.4(5.5)$ & $55.6(5.4)$ & $0.97[0.91 ; 1.03]$ & 0.30 & $0.97[0.91 ; 1.03]$ & 0.31 & $0.95[0.89 ; 1.02]^{7}$ & 0.15 \\
\hline \multicolumn{9}{|c|}{$\mathrm{NO}_{2}$ concentration, $50 \mathrm{~m}$ radius buffer $\left(\mu \mathrm{g} / \mathrm{m}^{3}\right)$} \\
\hline First trimester & $24.3(8.0)$ & $24.7(7.8)$ & $0.94[0.86 ; 1.02]$ & 0.15 & $0.92[0.84 ; 1.01]$ & 0.09 & $0.93[0.83 ; 1.03]$ & 0.16 \\
\hline Second trimester & $24.2(8.0)$ & $24.5(7.7)$ & $0.96[0.87 ; 1.04]$ & 0.31 & $0.93[0.85 ; 1.02]$ & 0.14 & $0.94[0.85 ; 1.05]$ & 0.27 \\
\hline Third trimester ${ }^{4}$ & $24.2(7.9)$ & $24.5(7.7)$ & $0.95[0.87 ; 1.04]$ & 0.25 & $0.93[0.85 ; 1.02]$ & 0.13 & $0.93[0.84 ; 1.04]$ & 0.22 \\
\hline Entire pregnancy & $24.2(7.6)$ & $24.5(7.4)$ & $0.94[0.86 ; 1.03]$ & 0.20 & $0.92[0.84 ; 1.02]$ & 0.10 & $0.93[0.83 ; 1.04]$ & 0.18 \\
\hline $\begin{array}{l}\text { The two months } \\
\text { before delivery }\end{array}$ & $24.2(8.0)$ & $24.5(7.8)$ & $0.96[0.88 ; 1.05]$ & 0.34 & $0.94[0.86 ; 1.03]$ & 0.19 & $0.95[0.86 ; 1.06]$ & 0.36 \\
\hline \multicolumn{9}{|c|}{$\mathrm{PM}_{10}$ concentration, $50 \mathrm{~m}$ radius buffer $\left(\mu \mathrm{g} / \mathrm{m}^{3}\right)$} \\
\hline First trimester & $18.7(3.9)$ & $18.7(3.9)$ & $1.02[0.86 ; 1.22]$ & 0.80 & $1.00[0.84 ; 1.20]$ & 0.97 & $1.02[0.85 ; 1.23]$ & 0.81 \\
\hline Second trimester & $18.8(3.9)$ & $18.6(3.9)$ & $1.17[0.99 ; 1.39]$ & 0.07 & $1.11[0.93 ; 1.32]$ & 0.26 & $1.13[0.95 ; 1.36]$ & 0.18 \\
\hline Third trimester ${ }^{4}$ & $18.9(4.0)$ & $18.6(4.0)$ & $1.21[1.03 ; 1.43]$ & 0.02 & $1.16[0.98 ; 1.38]$ & 0.09 & $1.19[1.00 ; 1.41]$ & 0.06 \\
\hline Entire pregnancy & $18.8(2.6)$ & $18.6(2.7)$ & $1.29[1.00 ; 1.66]$ & 0.05 & $1.18[0.91 ; 1.53]$ & 0.21 & $1.25[0.95 ; 1.64]$ & 0.11 \\
\hline $\begin{array}{l}\text { The two months } \\
\text { before delivery }\end{array}$ & $18.9(4.1)$ & $18.5(4.2)$ & $1.20[1.02 ; 1.41]$ & 0.03 & $1.16[0.99 ; 1.37]$ & 0.08 & $1.18[1.00 ; 1.40]$ & 0.05 \\
\hline $\begin{array}{l}\text { Fetal growth } \\
\text { restriction }\end{array}$ & $\mathrm{N}=587$ & $\mathrm{~N}=8407$ & $\mathrm{~N}=8994$ & & $\mathrm{~N}=8994$ & & $\mathrm{~N}=8994$ & \\
\hline \multicolumn{7}{|c|}{ Total noise exposure (dB) building $\mathrm{L}_{\mathrm{Aeq}, 24 \mathrm{~h}}$} & $0.99[0.90 ; 1.09]^{6}$ & 0.80 \\
\hline Entire pregnancy $^{3}$ & $55.5(5.5)$ & $55.6(5.4)$ & $0.98[0.90 ; 1.06]$ & 0.55 & $0.98[0.90 ; 1.06]$ & 0.58 & $0.98[0.90 ; 1.06]^{7}$ & 0.61 \\
\hline \multicolumn{9}{|c|}{$\mathrm{NO}_{2}$ concentration, $50 \mathrm{~m}$ radius buffer $\left(\mu \mathrm{g} / \mathrm{m}^{3}\right)$} \\
\hline First trimester & $24.2(7.7)$ & $24.7(7.8)$ & $0.93[0.83 ; 1.03]$ & 0.18 & $0.92[0.82 ; 1.03]$ & 0.13 & $0.91[0.80 ; 1.04]$ & 0.15 \\
\hline Second trimester & $24.4(7.8)$ & $24.4(7.7)$ & $1.00[0.90 ; 1.11]$ & 0.97 & $0.98[0.87 ; 1.10]$ & 0.71 & $0.99[0.87 ; 1.13]$ & 0.91 \\
\hline Third trimester ${ }^{5}$ & $24.6(7.7)$ & $24.4(7.7)$ & $1.03[0.93 ; 1.15]$ & 0.56 & $1.01[0.90 ; 1.13]$ & 0.93 & $1.04[0.91 ; 1.19]$ & 0.54 \\
\hline Entire pregnancy & $24.4(7.4)$ & $24.5(7.4)$ & $0.98[0.88 ; 1.10]$ & 0.73 & $0.96[0.86 ; 1.08]$ & 0.54 & $0.97[0.85 ; 1.12]$ & 0.70 \\
\hline $\begin{array}{l}\text { The two months } \\
\text { before delivery }\end{array}$ & $24.7(7.8)$ & $24.4(7.8)$ & $1.04[0.93 ; 1.16]$ & 0.49 & $1.03[0.92 ; 1.15]$ & 0.66 & $1.06[0.93 ; 1.20]$ & 0.41 \\
\hline \multicolumn{9}{|c|}{$\mathrm{PM}_{10}$ concentration, $50 \mathrm{~m}$ radius buffer $\left(\mu \mathrm{g} / \mathrm{m}^{3}\right)$} \\
\hline First trimester & $18.4(3.8)$ & $18.7(3.9)$ & $0.78[0.63 ; 0.98]$ & 0.03 & $0.77[0.61 ; 0.97]$ & 0.02 & $0.77[0.61 ; 0.97]$ & 0.03 \\
\hline Second trimester & $18.6(3.8)$ & $18.6(3.9)$ & $1.02[0.82 ; 1.26]$ & 0.87 & $0.96[0.77 ; 1.20]$ & 0.71 & $0.97[0.77 ; 1.22]$ & 0.78 \\
\hline Third trimester ${ }^{5}$ & $19.1(4.3)$ & $18.5(4.0)$ & $1.39[1.14 ; 1.70]$ & $<0.01$ & $1.35[1.09 ; 1.66]$ & $<0.01$ & $1.38[1.12 ; 1.70]$ & $<0.01$ \\
\hline Entire pregnancy & $18.7(2.7)$ & $18.6(2.7)$ & $1.05[0.77 ; 1.43]$ & 0.77 & $0.97[0.70 ; 1.33]$ & 0.85 & $0.99[0.71 ; 1.39]$ & 0.97 \\
\hline $\begin{array}{l}\text { The two months } \\
\text { before delivery }\end{array}$ & $19.1(4.4)$ & $18.5(4.2)$ & $1.35[1.11 ; 1.63]$ & $<0.01$ & $1.33[1.09 ; 1.62]$ & $<0.01$ & $1.35[1.11 ; 1.66]$ & $<0.01$ \\
\hline
\end{tabular}

Table 2. Relationship between noise, $\mathrm{NO}_{2}$ and $\mathrm{PM}_{10}$ exposure during pregnancy and small for gestational age or fetal growth restriction, 2005-2009 ( $\mathrm{N}=8994)$. N: number; $\mu(\mathrm{SD})$ : exposure average (standard deviation); OR: Odds ratio; CI: confidence interval. ${ }^{1}$ Wald Chi-square test. ${ }^{2}$ Adjusted for term, maternal age above 35 years at delivery, low neighborhood socioeconomic level, maternal smoking during pregnancy, malnutrition and obesity, nulliparity, gestational hypertension, diabetes, assisted reproductive techniques, vaginal bleeding in the second and third trimesters, infection, major infant congenital abnormalities. ${ }^{3}$ For $\mathrm{NO}_{2}$ and $\mathrm{PM}_{10}$ indices in adjusted analyses (the results were similar with the other period indices). ${ }^{4}$ Missing data for delivery before 29 weeks of gestational age $(n=106) .{ }^{5}$ Missing data for delivery before 29 weeks of gestational age $(\mathrm{n}=107) .{ }^{6}$ Noise and $\mathrm{NO}_{2} \cdot{ }^{7}$ Noise and $\mathrm{PM}_{10}$.

concentration and FGR became non-significant and the other estimates did not been change (Supplementary Table S10).

\section{Discussion}

Beyond studies with high levels of noise and air pollution, the situation with low levels of air pollution makes it possible to better assess the effect of noise on the relationship between air pollution and fetal growth disorders, avoiding a potential masking effect by high levels of air pollution. The systematic two-exposure modeling allowed to explore for confounding of noise on the relationship between air pollution and fetal growth. In our study, we first confirmed the previously observed association between moderate exposure to $\mathrm{PM}_{10}$ and fetal growth disorders, especially towards the end of pregnancy. Our results are also in favor of a lack of association between environmental noise exposure and fetal growth disorders in singletons. Finally, our data suggest that 
moderate exposure to noise has no confounding or modifying effect on the relationship between fetal growth and environmental exposure to the air pollution analyzed.

Air pollution, noise and fetal growth. In a context of moderate levels of air pollution, our results are in favor of an independent association between air pollution, and of a lack of association between noise and $\mathrm{NO}_{2}$ exposure and fetal growth disorders.

Air pollution and fetal growth. Most of the studies that found that air pollution $\left(\mathrm{NO}_{2}\right.$ or $\left.\mathrm{PM}_{10}\right)$ had a negative impact on fetal growth (SGA or FGR) were conducted on more polluted areas than in our study (1.5 to twofold more for $\mathrm{NO}_{2}$ and 2 to threefold more for $\left.\mathrm{PM}_{10}\right)^{21,55-60}$. Our results confirm that exposure to $\mathrm{PM}_{10}$ at the end of the pregnancy has a negative impact on FGR in a moderately polluted area. However, it could not be excluded that the study of finer particles would have led to different results (data were unfortunately not available for our study area). A study conducted in Vancouver, Canada, where the levels of $\mathrm{NO}_{2}$ were comparable to those of our study area, also described a negative impact of $\mathrm{NO}_{2}$ on $\mathrm{SGA}^{61}$. Other studies found no associations between $\mathrm{NO}_{2}$ and SGA ${ }^{27,62-65}$. The OR in our study ranged between 0.92 and 0.96 and were not significant. We conducted a precedent study in a population of multiple pregnancies (twins and triplets) and found no association between $\mathrm{NO}_{2}$ exposure and SGA with non-significant OR ranged between 0.78 and 0.88 , but an association between $\mathrm{NO}_{2}$ exposure and FGR with OR ranged between 1.42 and $1.52^{35}$.

Noise and fetal growth. In agreement with our results, a recent meta-analysis conducted by Dzhambov and Lercher found no association between noise and SGA (OR for an increase of $10 \mathrm{~dB}(\mathrm{~A})=1.02$; $95 \%$ CI 0.86 , 1.21) $\left(\mathrm{I}^{2}=90 \%\right)^{66}$. This meta-analysis was performed on five populations in four cohort or cross-sectional studies $^{27,29,32,67}$. However, levels of noise exposure were moderate in our study and associations between noise and fetal growth disorders could be plausible at higher levels of exposure.

Multiexposure to noise and air pollution, and fetal growth. Our study is one of the rare studies exploring coexposure to environmental noise and air pollution. Other studies have not specifically explored the influence of noise on the relationship between air pollution and fetal growth disorders, and have used different methods in contexts different from ours. In the metropolitan area of Vancouver, Canada, Gehring et al. found an association between all transportation noise exposure and SGA. The observed association between $\mathrm{NO}_{2}$ exposure and SGA differed according to the assessment of exposure: the OR associated with an IQR increase was $0.98(95 \%$ CI 0.96-1.01) when a land-use regression model was used and 1.10 (95\% CI 1.06-1.15) for the inversed distance weighting method. In co-pollutant models, only noise was associated with $\mathrm{SGA}^{29}$. In two surveys in the Alpine area, a positive association between noise and SGA was revealed in two-exposure model with adjustment for $\mathrm{NO}_{2}$ exposure, which was not associated with SGA in the first survey. In the second survey, noise was negatively associated with SGA though this association disappeared with adjustment for $\mathrm{NO}_{2}$ exposure ${ }^{67}$. In London, Smith et al. found no association between $\mathrm{NO}_{2}, \mathrm{PM}_{10}$, noise and SGA in one and co-pollutant models ${ }^{32}$.

Other studies analyze the association between noise, air pollution and (term-) birth weight or (term-) LBW or birth weight ${ }^{26-28,30,31}$. Two ecological time-series studies in Madrid, Spain, assessed the impact of $\mathrm{PM}_{2.5}, \mathrm{NO}_{2}$, $\mathrm{O}_{3}$, noise, and temperature on LBW and found an impact on LBW of: (1) daily diurnal noise at onset of gestation, in the second trimester and in the week of birth itself, and of $\mathrm{NO}_{2}$ in the second trimester, in all live singleton births for the first study; (2) only of $\mathrm{PM}_{2.5}$ in non-preterm births for the second study ${ }^{26,28}$. A cohort study in Barcelona, Spain, based on singleton term births found no effect of noise but an effect of $\mathrm{PM}_{2.5}$ and $\mathrm{PM}_{10}$ in the third trimester on $\mathrm{LBW}^{27}$. In a study on the Danish National Birth Cohort, no association between road traffic noise and $\mathrm{NO}_{2}$ on birth weight was found in children born at term in two exposure models ${ }^{30}$. Finally, a study grouping six European birth cohorts found no association between $\mathrm{NO}_{2}, \mathrm{PM}_{10}, \mathrm{PM}_{2.5}$, road traffic noise and $\mathrm{LBW}^{31}$.

Potential biases, study limits and strengths. The negative association between $\mathrm{PM}_{10}$ exposure during the first trimester and FGR could be explained by the combined effects of three factors: the effect of the exposure on fetal growth, the seasonal variations of the exposure, and the existence of a gestational period of sensitivity to exposure. In fact, $\mathrm{PM}_{10}$ levels vary in a 1-year cycle and are higher in the colder season than in warmer season due to anthropic activities (transport and heating). The seasonal variations are higher for $\mathrm{PM}_{10}$ than $\mathrm{NO}_{2}$. The duration of a pregnancy is 9 months. So when the first trimester of a pregnancy is in winter, then the third trimester will be in summer; $\mathrm{PM}_{10}$ levels will be higher in the first trimester than in the third. Conversely, when the first trimester of a pregnancy is in summer, the third will be in winter; $\mathrm{PM}_{10}$ levels will be higher in the third trimester than in the first. This is consistent with the sensitivity analysis adjusted for year-season of conception where the OR for the first trimester became non-significant. The mechanism of placental hypoperfusion intervenes especially at the end of pregnancy on fetal growth. In the hypothesis of an impact of $\mathrm{PM}_{10}$ on fetal growth, women with a third trimester in winter may experience more frequently FGR than women with a third trimester in summer. Higher $\mathrm{PM}_{10}$ levels will be associated with the occurrence of FGR, the observed OR may be greater than one for the third trimester exposure. Conversely, for women with a first trimester in the summer associated with lower $\mathrm{PM}_{10}$ levels, the observed OR may be lower than one for the first trimester exposure. This could potentially lead to seasonality bias. Moreover, as suggested by Hao et al. and by Raz et al., we cannot exclude a selection bias called live-birth bias at the beginning of the pregnancy due to early abortions that can be caused by exposure to air pollution because they were not detectable in our study and therefore were not included ${ }^{68,69}$. Raz et al. described two types of live-birth bias: (1) the selection of a group among whom those with high exposure to air pollution could have low exposure to other risk factors for FGR (or higher exposure to protective factors), or 
(2) the selection of a group among whom those with high exposure to air pollution could have lower susceptibility to the effects of other risk factors for FGR than those with lower air-pollution exposure.

Compared to the single pregnancies recorded in the 2010 French perinatal study, our study sample presented just slightly adverse outcomes ${ }^{70}$. In fact, the two maternities included are level 3 maternity units where complicated pregnancies are more closely monitored. But the two public university hospitals included in the study are also obstetrical primary care hospitals. So because of their immediate proximity for women living in the studied urban areas, the effect of the reference status of the two maternities is limited.

SGA and FGR seem to be the most relevant indicators of fetal growth abnormalities. In fact, the sexually dimorphic differences in growth of the fetus is mediated by the sex specific function of the human placenta ${ }^{71}$ and SGA and FGR take into account the sex of the fetus. They were defined differently. On one hand, SGA is defined as a weight lower than the 10th centile of weight for gestational age and sex. This indicator was objectively determined from the French perinatal network reference of birth weight for sex and gestational age ${ }^{36}$. When it was compared with another reference; the associations were similar. On the other hand, FGR was established from the ICD10 codes listed in medical records. FGR is defined as a defect in fetal growth on two antenatal measurements two to three weeks apart according to French, British, and Canadian recommendations ${ }^{38-40}$. FGR is rarely used as an outcome in environmental epidemiological studies because it is more difficult to diagnose FGR retrospectively than $\mathrm{SGA}^{58}$. However, SGA is defined by birth weight at gestational age and sex and the size and weight of newborns are strongly influenced by those of their parents. Moreover, SGA does not take into account the growth trajectory as opposed to FGR, which is a dynamic measure of growth regardless of the measured weight value. So SGA could be less specifically a disorder of fetal growth than FGR, and seems less appropriate for identifying an association between fetal growth disorders and environmental exposure than FGR. A coding effect cannot be ruled out because FGR implies a dynamic evaluation of fetal growth during pregnancy by obstetricians. However, this potential coding effect was reduced by the multicentric quality of this study.

Specific attention was paid to the collection of data from medical records. The consultation of paper medical records resulted in the collection of potential confounding factors for the adjustment of the analyses. Data was missing for two adjustment factors of the model (malnutrition/obesity and maternal smoking during pregnancy) but involved only $2.4 \%$ of pregnancies.

Another limit was the absence of information about a potential move during pregnancy - we used the mother's address at delivery, which was recorded in the hospital information system upon admission, for geocoding.

Individuals spend about $80 \%$ of the time in indoor environments (European Commission, 2004) and French women spend $16 / 24 \mathrm{~h}$ (67\% of the time) inside their dwelling ${ }^{72}$, but we did not use indoor air measurements for our study. Due to the retrospective design of this study, $\mathrm{NO}_{2}$ exposure was assessed using modelled outdoor exposure. However, a study in Vancouver, Canada, found a good agreement between indoor air measurements and outdoor values obtained by modeling ${ }^{73,74}$; a similar approach previously conducted by our team in the study area led to similar conclusions ${ }^{46,47}$; furthermore the retrospective modeling of exposure allowed for repeatable assessment of exposure. We assessed only residential exposure but time spent at home increases during maternity leave. We cannot however exclude exposure misclassification; but the definition of the air pollution and noise indicators that we used in this study has been explored in precedent works of our team ${ }^{49,50}$. Particular attention was paid to calculate $\mathrm{NO}_{2}$ and $\mathrm{PM}_{10}$ exposure closest to the home in the immediate neighborhood ${ }^{50}$. We used the average noise of all façades because the use of the noise of the most (least) exposed façade could induce an over (under) estimation of the exposure. Furthermore, the closer from the main source the building is located, the higher the overestimation could be. So when considering individual exposure, the most exposed façade could lead to differential error measurement. And last, this influence of the proximity of the source on the error assessment is more marked for noise than for air pollution. Moreover, we do not know the floor and the façade of the dwelling of the women included in our study. In one of the two areas, $25 \%$ of the buildings are very close to a main road. All these points could lead to a significant overestimation of the noise exposure of the most exposed buildings ${ }^{49}$, and then to a high risk of differential error assessment between dwelling, and between noise and air pollution exposure.

\section{Conclusions}

The study confirms a positive association between fetal growth disorders in single pregnancies and environmental exposure to air pollution at the end of pregnancy, in moderately polluted cities. In these conditions of moderate noise exposure, no argument in favor of a noise effect on the relationship between fetal growth and environmental exposure to air pollution was found in our study. These results need to be confirmed in areas with high levels of noise so as not to overlook the effect of high exposure of noise on the relationship between air pollution and fetal growth disorders.

\section{Data availability}

In accordance with the CNIL recommendations and the letter of information sent to each eligible family, we are not authorized to transmit the data.

Received: 22 December 2020; Accepted: 17 May 2021

Published online: 27 May 2021

\section{References}

1. Colella, M., Frérot, A., Novais, A. R. B. \& Baud, O. Neonatal and long-term consequences of fetal growth restriction. Curr. Pediatr. Rev. 14(4), 212-218 (2018).

2. Dall'Asta, A., Brunelli, V., Prefumo, F., Frusca, T. \& Lees, C. C. Early onset fetal growth restriction. Matern. Health Neonatol. Perinatol. 18(3), 2 (2017). 
3. Figueras, F. \& Gardosi, J. Intrauterine growth restriction: new concepts in antenatal surveillance, diagnosis, and management. Am. J. Obstet. Gynecol. 204(4), 288-300 (2011).

4. Gardosi, J. \& Francis, A. Adverse pregnancy outcome and association with small for gestational age birthweight by customized and population based percentiles. Am. J. Obstet. Gynecol. 201(28), e1-8 (2009).

5. Kady, S. \& Gardosi, J. Perinatal mortality and fetal growth restriction. Best Pract. Res. Clin. Obstet. Gynaecol. 18(3), 397-410 (2004).

6. Sharma, D., Farahbakhsh, N., Shastri, S. \& Sharma, P. Intrauterine growth restriction: part 2. J. Matern. Fetal Neonatal. Med. 29(24), 4037-4048 (2016).

7. Barker, D. J. et al. Fetal nutrition and cardiovascular disease in adult life. Lancet 341(8850), 938-941 (1993).

8. Figueras, F. \& Gratacos, E. An integrated approach to fetal growth restriction. Best Pract. Res. Clin. Obstet. Gynaecol. 38, 48-58 (2017).

9. Jacobsson, B. et al. Cerebral palsy and restricted growth status at birth: population based case-control study. BJOG 115(10), $1250-1255$ (2008).

10. Tenailleau, Q. M. et al. Do outdoor environmental noise and atmospheric $\mathrm{NO}_{2}$ levels spatially overlap in urban areas?. Environ. Pollut. 214, 767-775 (2016).

11. Biberoglu, E. et al. Circulating and myometrial markers of oxidative stress in pregnant women with fetal growth restriction. J. Obstet. Gynaecol. Res. 42(1), 29-35 (2016).

12. Browne, V. A. et al. Uterine artery blood flow, fetal hypoxia and fetal growth. Philos. Trans. R Soc. Lond. B Biol. Sci. 370(1663), 20140068 (2015).

13. Daiber, A. et al. Environmental noise induces the release of stress hormones and inflammatory signaling molecules leading to oxidative stress and vascular dysfunction-Signatures of the internal exposome. BioFactors 45(4), 495-506 (2019).

14. Duhig, K., Chappell, L. C. \& Shennan, A. H. Oxidative stress in pregnancy and reproduction. Obstet Med. 9(3), 113-116 (2016).

15. Ghio, A. J., Carraway, M. S. \& Madden, M. C. Composition of air pollution particles and oxidative stress in cells, tissues, and living systems. J. Toxicol. Environ. Health B Crit. Rev. 15(1), 1-21 (2012).

16. Ha, S., Zhu, Y., Liu, D., Sherman, S. \& Mendola, P. Ambient temperature and air quality in relation to small for gestational age and term low birthweight. Environ. Res. 155, 394-400 (2017).

17. Møller, P. et al. Oxidative stress and inflammation generated DNA damage by exposure to air pollution particles. Mutat. Res. Rev. Mutat. Res. 762, 133-166 (2014).

18. Nieuwenhuijsen, M. J., Ristovska, G. \& Dadvand, P. WHO environmental noise guidelines for the european region: a systematic review on environmental noise and adverse birth outcomes. Int. J. Environ. Res. Public Health. 14(10), 1252 (2017).

19. Prada, J. A. \& Tsang, R. C. Biological mechanisms of environmentally induced causes of IUGR. Eur. J. Clin. Nutr. 52, S21-S27 (1998) (discussion S27-8)

20. Slama, R. et al. Meeting report: atmospheric pollution and human reproduction. Environ. Health Perspect. 116(6), 791-798 (2008).

21. Guo, L. Q. et al. Ambient air pollution and adverse birth outcomes: a systematic review and meta-analysis. J. Zhejiang Univ. Sci. B. 20(3), 238-252 (2019).

22. Huang, I. et al. A systematic review of associations between maternal exposures during pregnancy other than smoking and antenatal fetal measurements. Environ. Res. 173, 528-538 (2019).

23. Li, X. et al. Association between ambient fine particulate matter and preterm birth or term low birth weight: an updated systematic review and meta-analysis. Environ. Pollut. 227, 596-605 (2017).

24. Tsoli, S., Ploubidis, G. B. \& Kalantzi, O. I. Particulate air pollution and birth weight: a systematic literature review. Atmosph. Pollut. Res. 10(4), 1084-1122 (2019).

25. Zheng, T. et al. Effects of environmental exposures on fetal and childhood growth trajectories. Ann. Glob. Health. 82(1), 41-99 (2016)

26. Arroyo, V., Díaz, J., Carmona, R., Ortiz, C. \& Linares, C. Impact of air pollution and temperature on adverse birth outcomes: Madrid, 2001-2009. Environ. Pollut. 218, 1154-1161 (2016).

27. Dadvand, P. et al. Residential proximity to major roads and term low birth weight: the roles of air pollution, heat, noise, and roadadjacent trees. Epidemiology 25(4), 518-525 (2014)

28. Díaz, J., Arroyo, V., Ortiz, C., Carmona, R. \& Linares, C. Effect of environmental factors on low weight in non-premature births: a time series analysis. PLoS ONE 11(10), e0164741 (2016).

29. Gehring, U., Tamburic, L., Sbihi, H., Davies, H. W. \& Brauer, M. Impact of noise and air pollution on pregnancy outcomes. Epidemiology 25(3), 351-358 (2014).

30. Hjortebjerg, D. et al. Associations between maternal exposure to air pollution and traffic noise and newborn's size at birth: a cohort study. Environ. Int. 95, 1-7 (2016).

31. Nieuwenhuijsen, M. J. et al. Influence of the urban exposome on birth weight. Environ. Health Perspect. 127(4), 47007 (2019).

32. Smith, R. B. et al. Impact of London's road traffic air and noise pollution on birth weight: retrospective population based cohort study. BMJ 5(359), j5299 (2017).

33. Barba-Vasseur, M. et al. Do low to moderate environmental exposure to noise and air pollution influence preterm delivery in medium-sized cities?. Int. J. Epidemiol. 46(6), 2017-2027 (2017).

34. Brembilla, A. et al. Pregnancy vulnerability in urban areas: a pragmatic approach combining behavioral, medico-obstetrical, socio-economic and environmental factors. Sci. Rep. 9(1), 18878 (2019).

35. Mariet, A. S. et al. Multiple pregnancies and air pollution in moderately polluted cities: Is there an association between air pollution and fetal growth?. Environ. Int. 121(Pt 1), 890-897 (2018).

36. Association of users of computerized records in pediatrics, obstetrics and gynecology (Audipog). Presentation of the sentinel network, accessed 1st December 2020. https://www.audipog.net/Reseau-Sentinelle.

37. Ego, A. et al. Customized and non-customized French intrauterine growth curves: I: methodology. J. Gynecol. Obstet. Biol. Reprod. (Paris). 45(2), 155-164 (2016)

38. French national college of gynecologists and obstetricians (CNGOF). Recommendations for clinical practice. Intrauterine growth retardation. 37th national days. Paris, 2013, accessed 1st December 2020 http://www.cngof.asso.fr/data/RCP/CNGOF_2013_ FINAL_RPC_rciu.pdf.

39. Lausman, A. \& Kingdom, J. Maternal fetal medicine committee: Intrauterine growth restriction: screening, diagnosis, and management. J. Obstet. Gynaecol. Can. 35(8), 741-748 (2013).

40. Royal College of Obstetricians and Gynaecologists (RCOG). The investigation and management of the small-for-gestational age fetus. London (UK): Royal College of Obstetricians and Gynaecologists (RCOG); 2013 [Green-top guideline; No. 31].

41. EUROCAT. EUROCAT Guide 1.3: Instruction for the registration and surveillance of congenital anomalies. EUROCAT Central Registry, University of Ulster; 2005.

42. INSEE. National Institute of Statistic and Economics Studies. Definition of IRIS. 2016 Oct, accessed 1st December 2020 https:// www.insee.fr/en/metadonnees/definition/c1523.

43. Lalloué, B. et al. A statistical procedure to create a neighborhood socioeconomic index for health inequalities analysis. Int. J. Equity Health. 28(12), 21 (2013).

44. Messer, L. C. et al. The development of a standardized neighborhood deprivation index. J. Urban Health Bull. New York Acad. Med. 83(6), 1041-1062 (2006) 
45. Pornet, C. et al. Construction of an adaptable European transnational ecological deprivation index: the French version. J. Epidemiol. Commun. Health 66(11), 982-989 (2012).

46. Pujol, S. et al. Urban ambient outdoor and indoor noise exposure at home: a population-based study on schoolchildren. Appl. Acoust. 73, 741-750 (2012).

47. Pujol, S. et al. Indoor noise exposure at home: a field study in the family of urban schoolchildren. Indoor Air 24(5), 511-520 (2014).

48. Pujol, S. et al. Association between ambient noise exposure and school performance of children living in an urban area: a crosssectional population-based study. J. Urban Health. 91(2), 256-271 (2014).

49. Tenailleau, Q. M. et al. Assessing residential exposure to urban noise using environmental models: Does the size of the local living neighborhood matter?. J. Expo. Sci. Environ. Epidemiol. 25(1), 89-96 (2015).

50. Tenailleau, Q. M., Mauny, F., Joly, D., François, S. \& Bernard, N. Air pollution in moderately polluted urban areas: How does the definition of "neighborhood" impact exposure assessment?. Environ. Pollut. 206, 437-448 (2015).

51. EEA (2011). Air Quality in Europe. European Environment Agency, Luxemburg (Luxemburg) (Technical report).

52. World Health Organization Europe (2003). Health Aspects of Air Pollution with Particulate Matter, Ozone and Nitrogen Dioxide. World Health Organization - Regional Office for Europe. Copenhagen (Denmark).

53. EEA (2011). The Application of Models under the European Union's Air Quality Directive. European Environmental Agency, Luxembourg (Luxembourg).

54. Commission, E. Directive 2002/49/EC of the European Parliament and of the Council of 25 June 2002 (European Parliament, 2002).

55. Ballester, F. et al. Air pollution exposure during pregnancy and reduced birth size: a prospective birth cohort study in Valencia, Spain. Environ. Health. 29(9), 6 (2010).

56. Liu, S., Krewski, D., Shi, Y., Chen, Y. \& Burnett, R. T. Association between gaseous ambient air pollutants and adverse pregnancy outcomes in Vancouver, Canada. Environ. Health Perspect. 111(14), 1773-1778 (2003).

57. Liu, S., Krewski, D., Shi, Y., Chen, Y. \& Burnett, R. T. Association between maternal exposure to ambient air pollutants during pregnancy and fetal growth restriction. J. Expo. Sci. Environ. Epidemiol. 17(5), 426-432 (2007).

58. Nobles, C. J. et al. Ambient air pollution and fetal growth restriction: Physician diagnosis of fetal growth restriction versus population-based small-for-gestational age. Sci. Total Environ. 650(Pt 2), 2641-2647 (2019).

59. Wang, Q. et al. Seasonal analyses of the association between prenatal ambient air pollution exposure and birth weight for gestational age in Guangzhou, China. Sci. Total Environ. 1(649), 526-534 (2019).

60. Wang, Q. et al. Interaction of Air Pollutants and Meteorological Factors on Birth Weight in Shenzhen, China. Epidemiology 30(Suppl 1), S57-S66 (2019).

61. Stieb, D. M. et al. A national study of the association between traffic-related air pollution and adverse pregnancy outcomes in Canada, 1999-2008. Environ. Res. 148, 513-526 (2016).

62. Capobussi, M. et al. Air pollution impact on pregnancy outcomes in Como, Italy. J. Occup. Environ. Med. 58(1), 47-52 (2016).

63. Gehring, U. et al. Traffic-related air pollution and pregnancy outcomes in the Dutch ABCD birth cohort study. Occup. Environ. Med. 68(1), 36-43 (2011).

64. Hannam, K., McNamee, R., Baker, P., Sibley, C. \& Agius, R. Air pollution exposure and adverse pregnancy outcomes in a large UK birth cohort: use of a novel spatio-temporal modelling technique. Scand. J. Work Environ. Health. 40(5), 518-530 (2014).

65. Poirier, A. et al. Maternal exposure to air pollution and adverse birth outcomes in Halifax, Nova Scotia. J. Occup. Environ. Med. 57(12), 1291-1298 (2015).

66. Dzhambov, A. M. \& Lercher, P. Road traffic noise exposure and birth outcomes: an updated systematic review and meta-analysis. Int. J. Environ. Res. Public Health. 16(14), 2522 (2019).

67. Dzhambov, A. M., Markevych, I. \& Lercher, P. Associations of residential greenness, traffic noise, and air pollution with birth outcomes across Alpine areas. Sci. Total Environ. 15(678), 399-408 (2019).

68. Hao, J. et al. Association between ambient air pollution exposure and infants small for gestational age in Huangshi, China: a crosssectional study. Environ. Sci. Pollut. Res. Int. 26(31), 32029-32039 (2019).

69. Raz, R., Kioumourtzoglou, M. A. \& Weisskopf, M. G. Live-birth bias and observed associations between air pollution and autism. Am. J. Epidemiol. 187(11), 2292-2296 (2018).

70. Blondel B, Kermarrec M. Perinatal survey 2010. Births in 2010 and their evolution since 2003. 2011, accessed 1st December 2020. http://www.epopé-inserm.fr/wp-content/uploads/2015/01/Rapport-Naisances-ENP2010.pdf.

71. Clifton, V. L. Review: Sex and the human placenta: mediating differential strategies of fetal growth and survival. Placenta 31(Suppl), S33-S39 (2010).

72. Zeghnoun, A. \& Dor, F. Description du budget espace-temps et estimation de lexposition de la population française dans son logement. Saint-Maurice (Fra): Institut de veille sanitaire; 2010, accessed 1st December 2020. https://www.santepubliquefrance. fr/determinants-de-sante/exposition-a-des-substances-chimiques/monoxyde-de-carbone/documents/rapport-synthese/descr iption-du-budget-espace-temps-et-estimation-de-l-exposition-de-la-population-francaise-dans-son-logement.

73. Nethery, E., Leckie, S. E., Teschke, K. \& Brauer, M. From measures to models: an evaluation of air pollution exposure assessment for epidemiological studies of pregnant women. Occup. Environ. Med 65(9), 579-586 (2008).

74. Nethery, E., Teschke, K. \& Brauer, M. Predicting personal exposure of pregnant women to traffic-related air pollutants. Sci. Total. Environ. 395(1), 11-22 (2008).

\section{Acknowledgements}

The authors acknowledge the local associations for air quality monitoring: Atmo Franche-Comté and Atmosf'air Bourgogne; O. Allemandet, A. Bourtembourg, A. Dussaucy, A. Eckmann, M. Puyraveau and M. Vasseur-Barba from the Centre Hospitalier Régional Universitaire (CHRU) of Besançon; J. Besson and S. Belhadj from the CHRU of Dijon; S. Rankin for thorough proofreading of this article; and the Maison des Sciences de l'Homme et de l'Environnement (MSHE USR3124) for assistance in this project. Computations were performed on the supercomputer facilities at the Mésocentre de Calcul de Franche-Comté.

\section{Author contributions}

A.S.M., N.B., F.M. and C.Q. conceived the design of this present study; P.S., G.T. and D.R. provided its implementation and data collection; S.P., M.B., J.D. and H.H. conducted the environmental data collection and analysis; A.S.M., A.L.P. and E.B. conducted statistical analysis; All authors contributed to the interpretation of the results; A.S.M. drafted the manuscript; All authors critically revised the manuscript, read and approved the final manuscript.

\section{Funding}

This work was supported by the Agence De l'Environnement et de la Maitrise de l'Energie (ADEME) [1217C0065] as part of the National Environmental Research and Occupational Health Program 2012 from the French 
Agency for Food, Environmental and Occupational Health and Safety (ANSES), and the "Fondation de France" [00069262]. This paper presents the results from the second part of the PrémaBQuA project: Preterm Birth and Environmental Multiple Exposure: Noise and Air Urban Areas.

\section{Competing interests}

Authors ASM, NB, SP, GT, DR, MB, JD, HH, ALP, EB, FM and CQ do not declare any conflict of interest. Author PS received funding from the following commercial companies: Merck Serono, Finox Biotech, Ferring, MSD France SAS, Teva Santé SAS, Allergan France, Gedeon Richter France, Effik SA, Karl Storz Endoscopie France, GE Medical Systems SCS, Laboratoires Genevrier, HAC Pharma, and Ipsen. The authors confirm that none of this funding was used to support the research in this study. There are no patents, products in development or marketed products to declare. This does not alter the authors' adherence to all the ICMJE policies on sharing data and materials.

\section{Additional information}

Supplementary information The online version contains supplementary material available at https://doi.org/ 10.1038/s41598-021-90788-1.

Correspondence and requests for materials should be addressed to A.-S.M.

Reprints and permissions information is available at www.nature.com/reprints.

Publisher's note Springer Nature remains neutral with regard to jurisdictional claims in published maps and institutional affiliations.

(c) (i) Open Access This article is licensed under a Creative Commons Attribution 4.0 International License, which permits use, sharing, adaptation, distribution and reproduction in any medium or format, as long as you give appropriate credit to the original author(s) and the source, provide a link to the Creative Commons licence, and indicate if changes were made. The images or other third party material in this article are included in the article's Creative Commons licence, unless indicated otherwise in a credit line to the material. If material is not included in the article's Creative Commons licence and your intended use is not permitted by statutory regulation or exceeds the permitted use, you will need to obtain permission directly from the copyright holder. To view a copy of this licence, visit http://creativecommons.org/licenses/by/4.0/.

(C) The Author(s) 2021 